\title{
Crentes, pregadores, funkeiros e drags: 0 baile da diferença nas convenções de Bárbara Wagner
}

\section{PEDRO ERNESTO FREITAS LIMA}

\section{Resumo}

A partir da fotografia e do audiovisual, Bárbara Wagner produz representações do que chama de "corpo popular". O interesse da artista está em produzir imagens de corpos coletivos, a maioria participante da cena urbana de Recife. Pretendemos debater aqui a distância que a obra de Wagner mantém do estereótipo como mecanismo de representação identitária. Para isso, analisaremos duas séries de fotografias - Crentes e pregadores (2014), Mestres de cerimônias (2016) - e o vídeo Vai que fica (2015) a partir da discussão sobre identidade de autores pós-coloniais como Homi Bhabha e Stuart Hall.

Palavras-chave:

Bárbara Wagner, identidade, fotografia 


\title{
Believers, preachers, funkeiros and drags: the difference dance in Barbara Wagner's conventions
}

\section{PEDRO ERNESTO FREITAS LIMA}

\begin{abstract}
Using photography and audiovisual, Bárbara Wagner produces, how she calls, "popular body" representations. The artist interest to produce collective bodies images, mostly them take part in Recife'surban scene. We want to debate here the Wagner's work distance from the stereotype, understanding it as an identity representation mechanism. For this, we will analyze two series of photographs - Crentes e pregadores (2014), Mestres de cerimônias (2016) - and the video Vai que fica (2015) taking up the identity discussion of postcolonial authors such as Homi Bhabha and Stuart Hall.
\end{abstract}

Keywords:

Bárbara Wagner, identity, photography 


\section{Creyentes, predicadores, funkeiros y drags: el baile de la diferencia en las convenciones de Bárbara Wagner}

\section{PEDRO ERNESTO FREITAS LIMA}

\section{Resumen}

A partir de la fotografía y del audiovisual, Bárbara Wagner produce representaciones de lo que llama "cuerpo popular". El interés de la artista está en producir imágenes de cuerpos colectivos, en su mayoría participantes de la escena urbana de Recife. Pretendemos debatir aquí la distancia que la obra de Wagner mantiene del estereotipo como mecanismo de representación identitaria. Para ello, analizaremos dos series de fotografías - Crentes e pregadores (2014), Mestres de cerimônias (2016) - y el vídeo Vai que fica (2015) a partir de la discusión sobre identidad de autores postcoloniales como Homi Bhabha y Stuart Hall.

Palabras clave:

Bárbara Wagner, identidad, fotografía 
O interesse de Bárbara Wagner está naquilo que ela chama de "corpo popular". ${ }^{1}$ Radicada em Recife, a fotógrafa brasiliense de nascimento se interessa pelas imagens produzidas por performances populares coletivas, geralmente de caráter ritualístico, que instituem uma diferença, ou seja, que tornam identificável um determinado corpo coletivo, um grupo, devido às suas especificidades manifestadas e reiteradas. Tendo como referência os debates sobre identidade em uma perspectiva pós-colonial de Homi Bhabha e Stuart Hall, discutiremos aqui três trabalhos da artista - as séries fotográficas Crentes e pregadores (2014), Mestres de cerimônias (2016) e o vídeo Vai que fica (2015) - no que tange a como o estereótipo é operado no processo de representação. Diante da complexidade da discussão dos termos aqui envolvidos, - o próprio Hall alerta para o fato de que a comunidade sociológica está dividida em relação a essa questão. "As tendências são demasiadamente recentes e ambíguas". $\mathrm{O}$ conceito de identidade "é demasiadamente complexo, muito pouco desenvolvido e muito pouco compreendido na ciência social contemporânea para ser definitivamente posto à prova" (HALL, 2015, p. 9) - é necessário dizer que, evidentemente, esse trabalho se limita a ser uma proposta possível entre outros projetos de aproximação e de reflexão crítica sobre a obra da artista.

Ao serem observadas em conjunto, as fotografias de Wagner parecem tensionar em direção a dois sentidos opostos: ao mesmo tempo em que evidenciam traços identitários compartilhados por um grupo, também dão relevo - principalmente nos retratos individuais - às particularidades de seus integrantes. A operação dos recursos de representação pela fotógrafa visa a alcançar um tipo, um estereótipo. Pen- 
sando o estereótipo a partir de Homi Bhabha (2013, p. 134) como uma "forma limitada de alteridade" isto é, como uma simplificação não pelo fato de ser uma falsa representação, mas por fixar representações de modo a sustentar determinado discurso - conceito esse sobre o qual nos deteremos mais adiante - e estabelecendo-o como limite, nos perguntamos qual seria a distância do trabalho de Wagner dessa fronteira. Seria a adesão ao estereótipo um recurso para conceber um "corpo popular"? Como Wagner o opera na sua construção de representações?

Crentes e pregadores (2014) ${ }^{2}$ é constituído por fotografias de religiosos, em sua maioria evangélicos neopentecostais, frequentadores de igrejas das periferias de Recife. É possível identificar três sequências dentro da série. Na primeira, Wagner fotografou grupos de crentes em interiores de igrejas no momento do culto. Geralmente os indivíduos estão de olhos fechados, como se estivessem em transe religioso. A iluminação é dramática, contrastes entre luz e sombra são explorados ao gosto barroco. Em outra sequência, a fotógrafa realiza um tipo de trabalho que afirma preferir - e que observamos em outras de suas séries -, que consiste em retratos de corpo inteiro e frontais, nos quais o modelo olha para a câmera e é iluminado por um flash posicionado de forma oblíqua a ele. Tanto figura quanto fundo são igualmente focados. Finalmente, há uma sequência de líderes religiosos fotografados dentro de templos em seus altares/ palcos. Aqui, os objetos de serviço, isto é, o aparato de apoio ao culto, como caixas de som, instrumentos musicais, fios e cadeiras são evidenciados.

Podemos apontar como antecedente que de alguma forma ecoa na obra de Wagner a conhecida série Homens do século XX de August Sander (1876-1964). Iniciada na década de 1920, Sander também pretendia representar por meio da fotografia determinado grupo social, nesse caso de dimensão nacional. $\mathrm{O}$ fotógrafo entendia estar construindo tipos de forma a apreender o que seria a sociedade alemã no início do século XX. Seu interesse não estava apenas em registrar esses vários tipos, mas também em classificá-los em categorias sociais, profissionais, de gênero e relativas ao espaço, agrupando imagens em diferentes porta-fólios. Segundo Paulo José Rossi (2009, p. 9o), "os títulos [dos retratos] são referentes não ao indivíduo fotografado, mas ao tipo social que Sander acredita o sujeito representar: o indivíduo é desconsiderado em favor de um tipo genérico posto em cena." Essa desconsideração do 
indivíduo fica explícita no fato de que alguns dos modelos aparecem em mais de um retrato performando diferentes tipos e classificados igualmente de forma diversa.

Ainda segundo Rossi, o conceito estético que norteia Homens do século XX é o de "exatidão", isto é, o interesse pela "hiper-precisão de detalhes", pela "clareza da informação", que potencializaria a capacidade descritiva da imagem e que seria alcançado não só pela precisão técnica, mas também pelo método de classificação empregado por Sander. Essa tipologia classificatória seria:

uma tentativa de despojar os personagens de todos os aspectos contingentes e particulares, chamando atenção para elementos explícitos nas imagens dos fotografados, tais como vestuário, postura, ambiente (habitação, local de trabalho, meio rural ou urbano), profissão, posição social etc. (ROSSI, 2009, p. 92, grifo do autor).

Assim como Sander, o interesse de Wagner está em representar o "corpo popular" em sua dimensão coletiva, o que fica evidente no título da série, o qual sugere um elemento dentro de uma dimensão classificatória. Vista em conjunto, como em espaços expositivos nos quais as fotografias são apresentadas lado a lado, o trabalho de Wagner pode ser compreendido dentro de uma lógica de inventário. Os retratos como fragmentos do mundo e que constituem um arquivo, ao serem montados em uma ordem específica por meio do inventário, são recriados em uma nova ordem, alterando o modo concreto de quem os percebe. A montagem produz um território no qual, suscitando relações de equidade entre seus elementos constituintes em uma table, permite que sejam aproximados e relacionados entre si, sendo possível então elaborar um ponto de vista que pode ser compartilhado em um tableau (ABREU, 2011, p. 196, 115-118, 241).

No entanto, Wagner não adere à anulação da individualidade como faz Sander. Os retratos da série são intitulados com nomes próprios, provavelmente dos próprios fotografados, como em Juliana (Figura 1), o que marca algum tipo de especificidade. Assim como Sander, Wagner também se interessa por uma "hiper-precisão de detalhes". A escolha por fazer uso do flash, mesmo em ambientes já muito luminosos, torna detalhes nítidos ao acentuar seus contrastes por meio de uma iluminação homogênea, produzindo um tom de artificialismo. Vejamos como Wagner entende a função do flash em seu trabalho: 


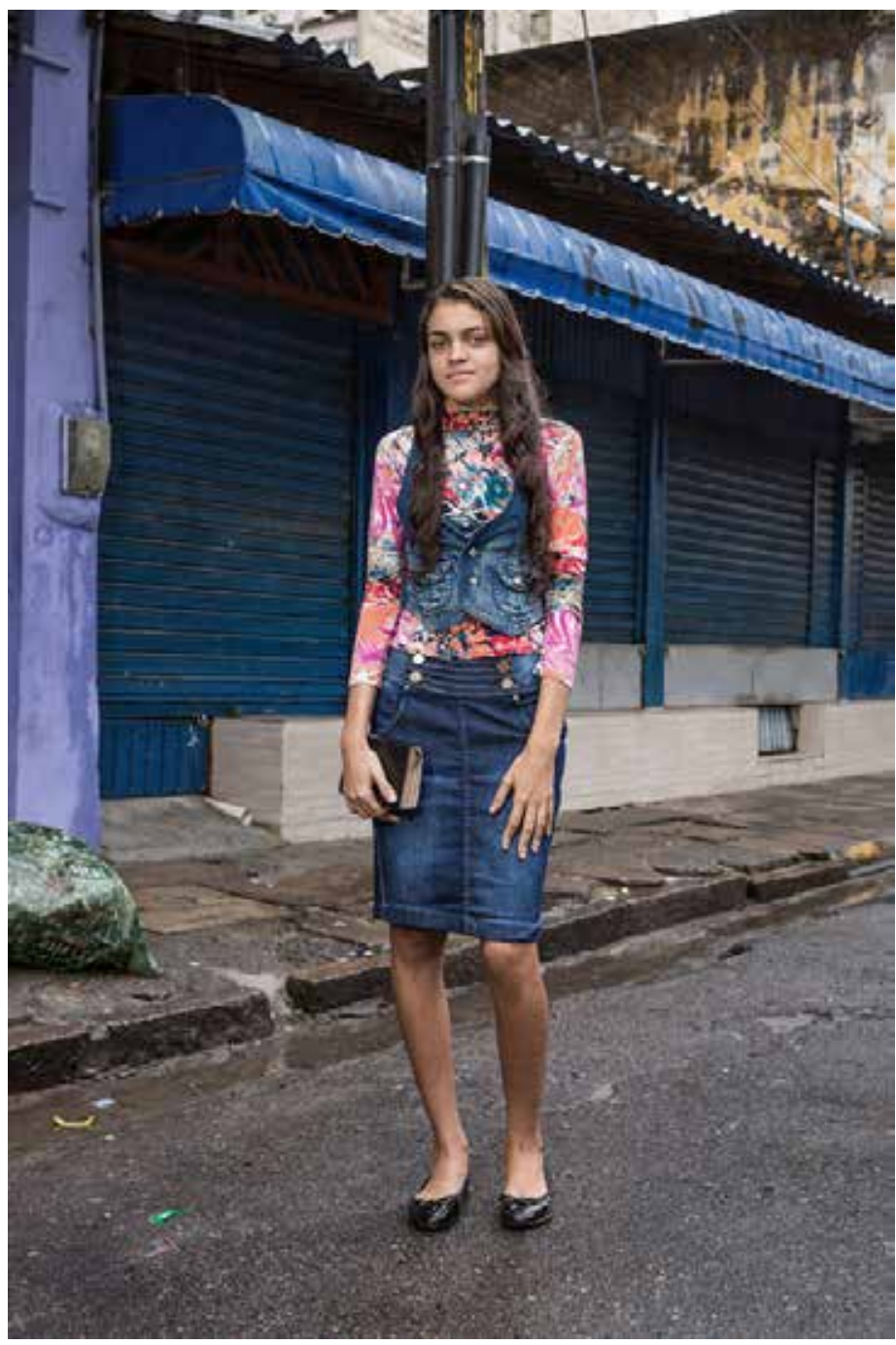

[...] os estereótipos são poderosos. Se existem códigos sutis criados, reproduzidos e adaptados em toda sorte de mídias a fim de representar status ou bom gosto, esses códigos só sobrevivem culturalmente porque funcionam. São os signos da propaganda, que não se diferenciam dos signos da política, em um sentido subjetivo também. Como me interesso por aquilo que é específico em determinada forma de expressão popular, faço uso de recursos da fotografia de retrato - da pose, do flash -, que trazem em sua superfície uma estética corriqueira, rapidamente compreendida não nas galerias de
Figura 1 - Juliana.

Fonte: Bárbara Wagner, da série Crentes e pregadores, 2014, jato de tinta sobre papel de algodão, $80 \times 120 \mathrm{~cm}$. 
arte, mas nas ruas. Porque no fundo, o que quero é me comunicar, fazer o trabalho falar. Em outras palavras, não tento reinventar a roda, mas gosto de entender como ela gira, e para que lado ela pode ir. (OLIVA, 2014, on-line).

Essas escolhas técnicas, incluído aí a opção pela fotografia colorida, juntamente ao interesse da fotógrafa pelo convencional, aproximam essas imagens daquelas de consumo de massa, de revistas de celebridades ou de anúncios de publicidade. Produzir uma imagem de consumo, digamos assim, é um argumento fundamental para Bárbara Wagner provocar o desejo de seus modelos por serem fotografados, ainda mais em um contexto no qual a produção de autorretratos (selfies) se tornou um ritual banal e ordinário devido à massificação de telefones celulares com recurso de câmera fotográfica. É necessário mencionar que seu interesse por investigar na produção artística uma linguagem assentada em convenções e em clichês, e por isso de assimilação rápida, está relacionado à sua formação em jornalismo e à sua atuação profissional inicial como fotojornalista ${ }^{3}$, linguagem que geralmente privilegia a pretensão à objetividade.

Percebemos nas imagens da série uma aproximação limitada entre modelo e fotógrafa na qual a empatia não passa de uma tentativa. Os modelos continuam distantes, como se estivessem mais preocupados em performar sua condição de grupo do que sua individualidade. $O$ resultado é próximo ao de uma tipologia etnográfica. A grande quantidade de indivíduos retratados, sempre ambientados nos locais que lhes são familiares, enfatiza a condição de grupo e sugere elementos, "rótulos", muitos deles recorrentes - o vestuário, o corte de cabelo, os acessórios, a postura -, que operam como vínculos identitários. É a partir desses "rótulos" que, para Kwame Anthony Appiah (2016, p. 18), os indivíduos "reagem aos outros e pensam sobre si mesmos", sendo, portanto, imprescindíveis para a existência de identidades sociais ainda que "contestáveis em suas fronteiras".

A partir dessa aproximação entre as fotografias de Crentes e pregadores e a tipologia etnográfica, convenção associada à produção de artistas viajantes, sobretudo do século XIX, e que poderia ser considerada como integrante de um conjunto de práticas denominadas por Achille Mbembe (2014, p. 153) como "ciência colonial" - uma documentação da diferença que aparentemente é um reconhecimento mas que, de fato, fixa-a em um cânone -, retomo a ideia de estereótipo 
de Bhabha. Devemos entender sua concepção de estereótipo como a principal estratégia discursiva do discurso colonial ${ }^{5}$ como produtor de "fixidez" na "construção ideológica da alteridade" (BHABHA, 2013, p. 117). Seu processo central é o da ambivalência, uma reiteração contínua e "ansiosa" de algo já conhecido, produzindo um efeito contraditório de impossibilidade de comprovação no discurso desse algo. Essa ambivalência dá validade ao estereótipo colonial, ao garantir

sua repetibilidade em conjunturas históricas e discursivas mutantes; embasa[r] suas estratégias de individuação e marginalização; produz[ir] aquele efeito de verdade probabilística e predictabilidade que, para o estereótipo, deve sempre estar em excesso do que pode ser provado empiricamente ou explicado logicamente. (BHABHA, 2013, p. 118).

Bhabha se interessa pelas imagens produzidas pelo estereótipo não em termos de positivo ou negativo, mas como possibilidade de compreensão de processos de subjetivação que elas tornam possíveis e plausíveis. "Julgar a imagem estereotipada com base em uma normatividade política prévia é descartá-la, não deslocá-la" (BHABHA, 2013, p. 118). É necessário, pois, considerar o regime de verdade do poder colonial ao invés de submeter essas imagens a um julgamento normatizante.

Podemos afirmar que o grande volume de imagens que Wagner produz em Crentes e pregadores é uma estratégia para reiterar "rótulos" identitários de forma contínua e "ansiosa", empregando aqui os termos de Bhabha, e que pressiona essas representações em direção à fixidez. Reconhecemos aqui, portanto, uma das formas com que a artista opera com o estereótipo em sua tarefa de representação do "corpo popular" sem, no entanto, aderir de forma total às suas estratégias, como veremos mais adiante. Reiteramos que, a partir de Bhabha, não interessa aqui fazer julgamento sobre a qualidade desses estereótipos, mas sim pensar em como se tornam possíveis enquanto imagem. Nesse momento é necessário perguntar quem é esse corpo coletivo representado nessa obra. Quem são os protagonistas das imagens de Wagner?

Segundo o Censo de 2010, entre os 86,8\% da população brasileira que se declarou cristã, $22,2 \%$ são evangélicos, que por sua vez estão vinculados a uma miríade de igrejas e que podem ser agrupadas sinteticamente em três segmentos: históricas (protestantes que aqui se instalaram no século XIX), 
pentecostais (do início do século XX, chamadas de igrejas de cura divina) e neopentecostais (do final do século XX, pregam a busca pela prosperidade material e são adeptas de práticas de exorcismo) (CUNHA, 2016, p. 4).

Os meios de comunicação desempenham um papel fundamental nas práticas desses grupos. Em alguns casos, as mídias fazem parte do projeto de criação/existência de algumas igrejas, bem como da essência de suas práticas (CUNHA, 2016, p. 9). A visibilidade da imagem do evangélico se intensifica nos anos 2000, tendo como meio privilegiado a televisão. Segundo Magali Nascimento Cunha, essa mídia favorece, além da propagação da fé cristã por meio da pregação religiosa, a formação de um mercado religioso por meio da oferta de produtos, entre eles a música gospel, instituindo uma concorrência entre as várias igrejas pela captação de público, o qual transcende à condição de fiel. A Teologia da Prosperidade, ao pregar o entendimento de que as conquistas de bens materiais são bênçãos divinas, é um argumento fundamental para as práticas dessa mídia cujo caráter é de publicidade institucional (CUNHA, 2016, p. 6). Esses eventos e essa ideologia dedicada aos problemas imediatos e práticos da vida terrena dificilmente podem ser pensados sem que consideremos que é também nesse período que se consolida o discurso oficial sobre a emergência de uma "nova classe média" no país constituída principalmente pela ascensão de indivíduos à classe $C$ (SINGER, 2012, p. 136-137), cuja característica distintiva é sua capacidade de consumo.

Ao contexto descrito acima podemos associar a ideia de "igreja eletrônica" proposta por Jesús Martín-Barbero para se referir ao uso fundamental de rádio e televisão como experiência religiosa por igrejas. Para ele, a "igreja eletrônica está devolvendo a magia às religiões que haviam se intelectualizado, que haviam esfriado, que haviam se desencantado." (MARTÍN-BARBERO,1995, p. 75-76 apud CUNHA, 2016, p. 11). A busca pela "magia" em detrimento do puramente "intelectualizado" auxilia na compreensão da religiosidade como entretenimento e consumo, e ainda a relação do crescimento da "nova classe média" - juntamente à sua disponibilidade para o consumo e eventualmente para conversão - com o avanço do neopentecostalismo.

Em Ministério Madureira (Figura 2), a dimensão prática e imediata da religiosidade é sugerida pelas caixas de pequenos eletrodomésticos localizadas no plano intermediário, atrás da pregadora. Dispostos sobre uma mesa e propositalmente 


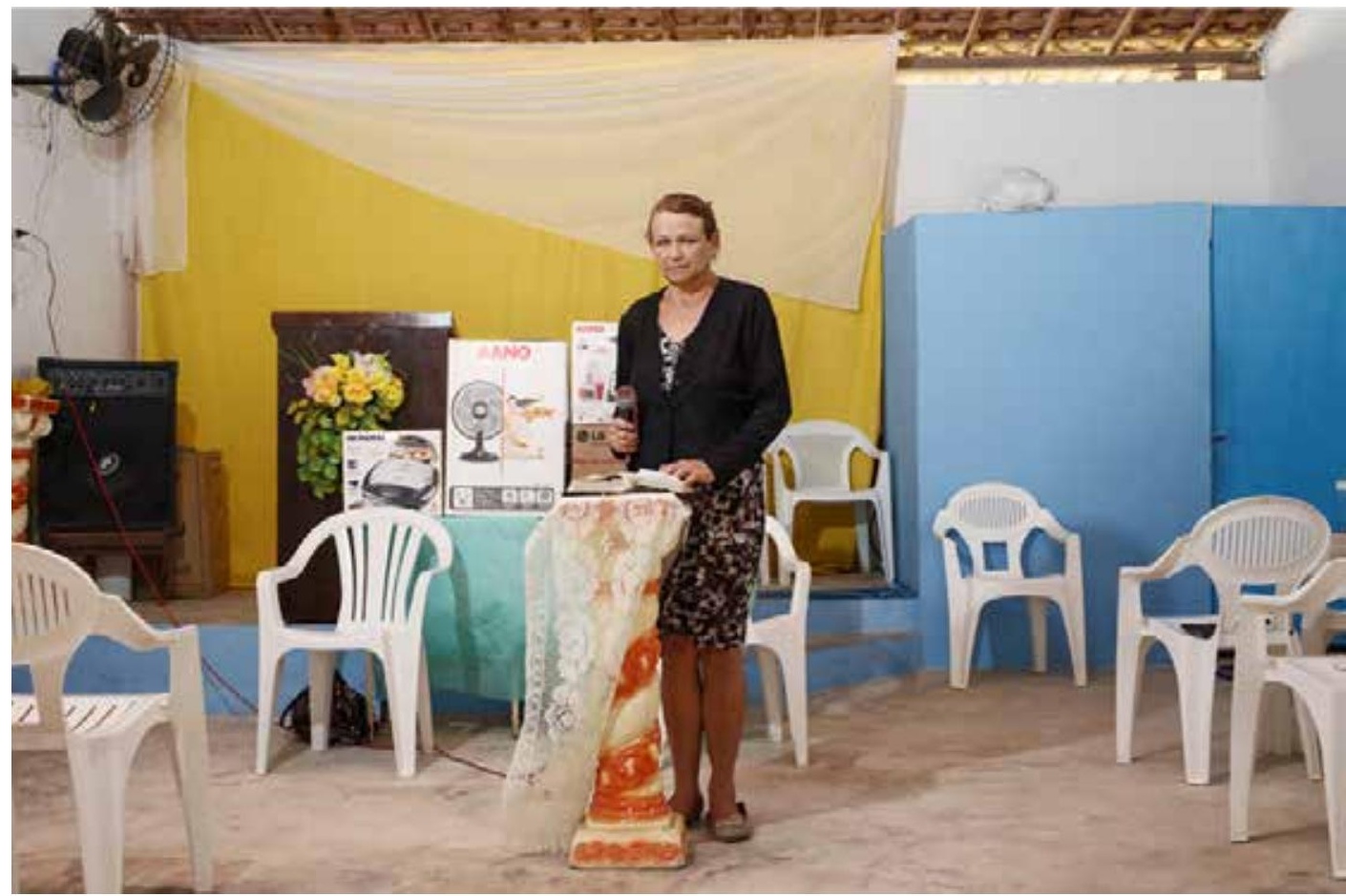

visíveis, vemos quatro produtos: uma sanduicheira Mondial, um ventilador, um liquidificador - ambos da marca Arno - e um micro-ondas LG. Não sabemos exatamente qual a função deles no contexto do culto: Seriam doações? Prêmios a serem sorteados entre os fiéis? Presentes de casamento a serem abençoados para então integrarem o lar de algum fiel? Sua disposição privilegiada - é relevante apontar o contraste entre a exposição desses produtos e a neutralidade do restante do cenário, em boa parte coberto por tecidos monocromáticos e sem estampas, preocupados em ocultar a estrutura precária indicada pelo telhado sem forro, de telhas aparentes, visível na parte superior da imagem - comunica o quanto esses pequenos facilitadores de atividades domésticas são relevantes para aquele grupo, pautando-os como objetos de desejo. Ministério Madureira contrasta com os cenários de outras imagens da série, os quais são ocupados geralmente por cortinados, paredes neutras ou imagens não idólatras como paisagens naturais.

Ao justificar seu trabalho, Wagner menciona a escassez de pesquisa visual sobre esse novo grupo emergente (INSTITUTO MOREIRA SALLES, 2015, on-line). A quantidade con-
Figura 2 - Ministério Madureira Fonte: Bárbara Wagner, da série Crentes e pregadores, 2014, jato de tinta sobre papel de algodão, $80 \times 120 \mathrm{~cm}$. 
siderável de pesquisas acadêmicas existentes sobre esse grupo concentra-se em áreas como ciências sociais, comunicação e música ${ }^{6}$, dado esse que surpreende já que estamos tratando de grupos religiosos para os quais a imagem midiática é inerente ao funcionamento de suas práticas religiosas.

Em outras séries, como, por exemplo, Brasília Teimosa (2005-2007), A corte (2013), e Mestres de cerimônias (2016), Wagner também busca representar outros grupos como os frequentadores de uma praia localizada em uma área precária de periferia, membros de um grupo de maracatu e profissionais das indústrias musicais do "Brega Funk" recifense e do "Funk Ostentação" paulista. Visando entender o processo de identificação e vinculação de indivíduos em torno dessas representações simbólicas de grupos a partir das quais é possível produzir tipos ou estereótipos, é oportuno mencionar o estudo de Stuart Hall sobre as estratégias de produção de representações identitárias. Apesar de seu interesse estar nas identidades nacionais, consideramos que sua discussão, redimensionando sua escala, pode nos auxiliar a pensar a obra de Wagner no que tange à representação identitária de uma comunidade local e de sua condição de pertencimento.

Para Hall (2015), apesar de tratarmos as identidades nacionais como parte da nossa natureza essencial, elas não são naturais, não estão dadas desde sempre, mas são discursos formados e transformados no interior da representação e que se utilizam de símbolos, construindo, portanto, identidades com as quais podemos nos identificar e integrar "comunidades simbólicas". Entre as estratégias de representação que acionamos para construir o senso comum sobre a identidade nacional que Hall (2015, p. 31-33) menciona estão a narrativa nacional, que representa as experiências compartilhadas e que dão significado e importância às nossas monótonas existências, nos conectando a um destino nacional que nos é preexistente e que continuará existindo a despeito de nós, enfatizando o que seriam as origens e a tradição; e os caracteres de continuidade e de intemporalidade que devem impregnar essa narrativa com um verniz do imutável .

De volta à nossa escala, para nosso estudo nos interessa a operação dos discursos das origens como produtores de tradição, daquilo que Joel Candau (2016, p. 95) denominou como "memória das origens", e que fundamenta representações identitárias. É importante mencionar que pouco importa, segundo Sélim Abou (1997, p. 4 apud CANDAU, 2016, p. 96-97), que a origem seja mitificada e que os legados culturais 
não sejam homogêneos totalmente. "O essencial é que esses elementos comuns são vividos pelo grupo em questão (ou, em todo caso, por uma parte de seus membros) como suas características distintivas e assim sejam percebidos pelos outros", o que contribui para a naturalização da comunidade.

Os códigos já mencionados compartilhados pelos modelos fotografados por Wagner e inscritos em seus corpos, modelando suas performatividades, nos mostram como os indivíduos "percebem-se [...] membros de um grupo e produzem diversas representações quanto à origem, história e natureza desse grupo" (CANDAU, 2016, p. 25-26), ainda que isso seja insuficiente para definir identidades. Ainda segundo Candau (2016, p. 26),

é provável que os membros de uma mesma sociedade compartilhem as mesmas maneiras de estar no mundo (gestualidade, maneiras de dizer, maneiras de fazer etc.), adquiridas quando de sua socialização primeira, maneiras de estar no mundo que contribuem a defini-los e que memorizaram sem ter consciência, o que é o princípio mesmo de sua eficácia.

Dessa forma, seria possível falar em "núcleo memorial", em um "fundo ou substrato cultural". No entanto, Candau faz uma ressalva, considerando abusivo o uso de expressões como "identidade cultural" ou "identidade coletiva" para designar "um suposto estado de um grupo inteiro quando apenas uma maioria dos membros desse grupo compartilha o estado considerado", entendendo como reducionista definir a identidade de um grupo "a partir unicamente da protomemória, pois as estratégias identitárias de membros de uma sociedade consistem em jogos muito mais sutis que o simples fato de expor passivamente hábitos incorporados." (2016, p. 27). Portanto, as identidades

[...] não se constroem a partir de um conjunto estável e objetivamente definível de "traços culturais" - vinculações primordiais -, mas são produzidas e se modificam no quadro das relações, reações e interações sociossituacionais - situações, contexto, circunstâncias -, de onde emergem os sentimentos de pertencimento, de "visões de mundo"identitárias ou étnicas. Essa emergência é a consequência de processos dinâmicos de inclusão e exclusão de diferentes atores que colocam em ação estratégias de designação e de atribuição de características identitárias reais ou fictícias, recursos simbólicos 
astros desse circuito - MCs, DJs e bailarinos - inseridos basicamente em dois tipos de cenários. Podem estar alocados em ambientes sóbrios, ao gosto daquilo que convencionalmente chamamos de elite geralmente considera como elegante e de bom gosto, como em Hugo (2016) (Figura 3). Sua roupa estampada, seus óculos de lentes coloridas, os cabelos descoloridos e a tatuagem no antebraço constroem um estereótipo de classe que contrasta com o ambiente. No entanto, o modelo publiciza sua possibilidade de estar naquele ambiente, provavelmente possibilitado pelo dinheiro e fama que a música lhe trouxe. Assim como em várias outras imagens da série, são evidenciados os equipamentos técnicos usados em set de filmagem.

Já em outras imagens a ostentação da condição de celebridade ocorre em ambientes de periferia urbana, como é o caso de Jessica (2016) (Figura 4). No último plano da imagem, vemos um emaranhado de fios e uma fachada de casa completamente coberta por grades. A modelo, usando um vestuário que dificilmente provocaria a indiferença - blusa com estampa imitando pele de animal, calça vermelha, relógio de pulso e
Figura 4-Jessica.

Fonte: Bárbara Wagner, Jessica, da série Mestres de cerimônias, 2016.

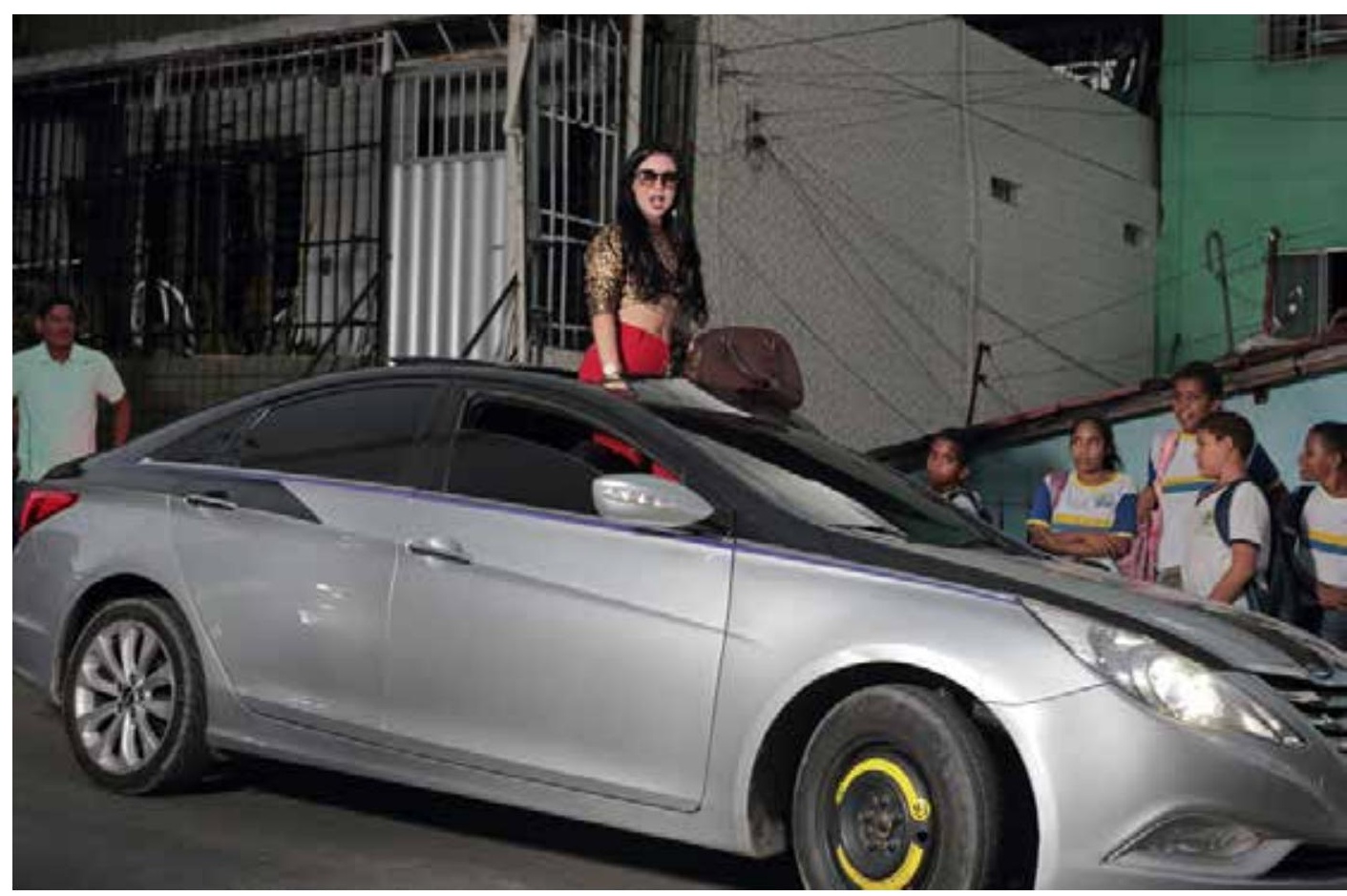


Figura 5 - Faz que vai.

Fonte: Bárbara Wagner e Benjamin de Burca, 2015.

2K, HD, cor, som, 16:9,12min.

(Parte I) Ryan, frevo/electro. óculos escuros que protegeriam do sol se dia fosse - poderia ser uma frequentadora comum do baile se não fosse o fato de ostentar um carro com linhas aerodinâmicas e com teto solar, acessório que faz questão de evidenciar. O homem de meia idade e os estudantes presentes ao fundo funcionam como espectadores, já que a imagem da mulher é para ser consumida.

Se em Crentes e pregadores, Wagner simula a linguagem do mundo do espetáculo, e para isso constrói o que poderíamos chamar de um vocabulário representativo que tira proveito operativo do estereótipo, em Mestres de cerimônias o vocabulário que estereotipa parece já estar dado e é exacerbado pela linguagem cenográfica do videoclipe, a qual media a fotógrafa e os astros musicais.

Em outros trabalhos, Wagner explora outras dimensões desse mecanismo, como em Faz que vai (2015), vídeo, dividido em quatro partes, realizado em parceria com Benjamin de Burca no qual a artista investiga a presença e a transformação da tradição no corpo de jovens dançarinos que, de forma ousada, experimentam o frevo combinado a outros tipos de dança (electro, vogue, swingueira e funk $)^{7}$. O frevo, executado pela conhecida Orquestra Popular da Bomba do Hemetério e presente na obra como índice da tradição e do discurso oficial que o tornou elemento identitário fundamental do estado de Pernambuco, contrasta com corpos e coreografias não usuais para sua execução padrão.
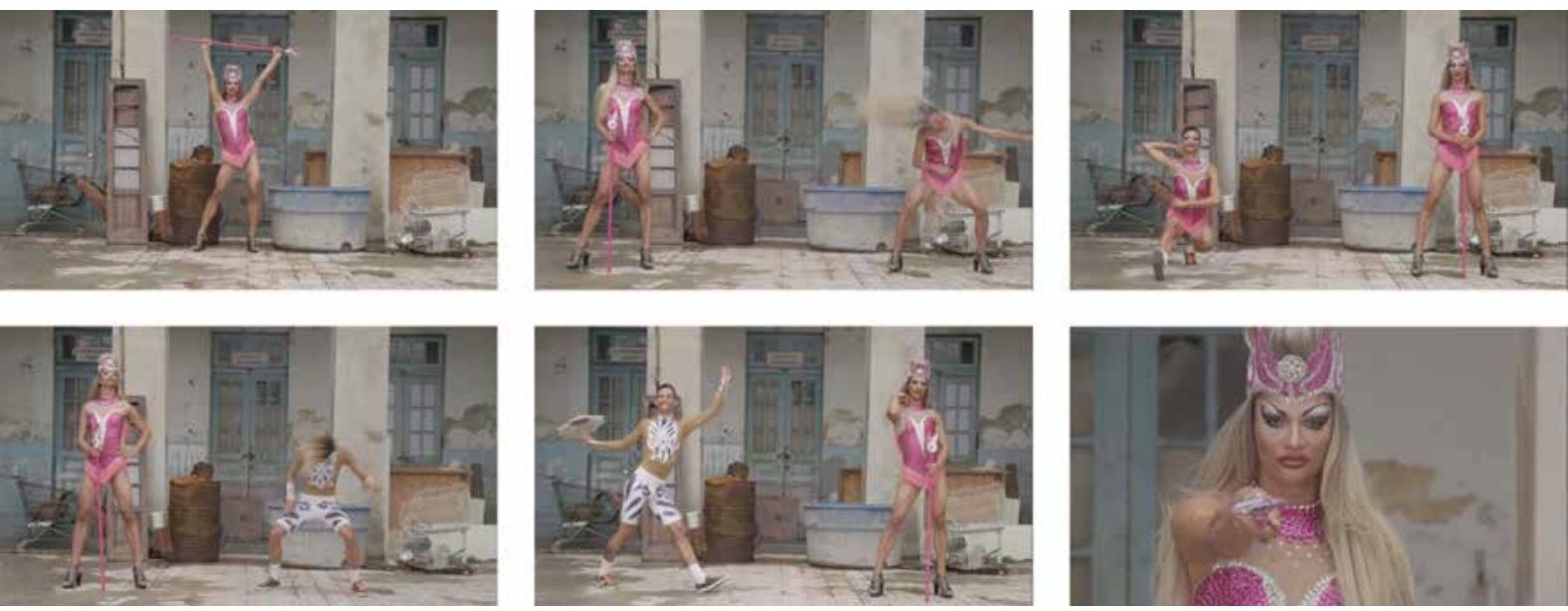

A parte I (Ryan, Frevo/Electro) é protagonizada por Ryan, dançarino que se apresenta na noite recifense como a drag 
queen Alice, cuja caracterização remete a uma heroína. Dotada de poderes especiais, com o seu bastão ela faz aparecer e desaparecer um duplo, encarnando outros papéis. Numa primeira aparição, executa uma coreografia de "bate cabelo", popular entre drags e travestis em festas gays. Na aparição seguinte, usando a mesma roupa de $d r a g$, dança o frevo em sua forma padrão. Em seguida, a mais uma desaparição e reaparição, executa novamente o "bate cabelo", mas dessa vez com roupa de passista de frevo. Finalmente, o dançarino reaparece e dança o frevo novamente vestido de passista e com sombrinha na mão.

Faz que vai é o nome de um passo do frevo no qual é simulado um momento de instabilidade. O vídeo embaralha e mistura representações identitárias de corpos e performances: a drag também dança frevo, o passista também executa o "bate cabelo". Estamos diante do que Bhabha (2013, p. 19) denomina como "figuras complexas de diferença e identidade". O que se verifica em nossos dias, segundo Bhabha (2013, p. 20), é o afastamento das singularidades de "classe" ou de "gênero" "como categorias conceituais e organizacionais básicas" em direção a uma consciência - "de raça, gênero, geração, local institucional, localidade geopolítica, orientação sexual" - que subsidia suas pretensões à identidade (grifo nosso), seja ela qual for.

O que é teoricamente inovador e politicamente crucial é a necessidade de passar além das narrativas de subjetividades originárias e iniciais e de focalizar aqueles momentos ou processos que são produzidos na articulação de diferenças culturais. (BHABHA, 2013, p. 20, grifo nosso).

Esses espaços de "articulação", ou seja, os "entre-lugares", são territórios onde são elaboradas estratégias de subjetivação - singular ou coletiva - produtoras de novos signos de identidade, de lugares de colaboração e contestação, de forma que a própria ideia de sociedade é definida.

Instigado pela artista Renée Green quando esta diz que "É preciso que a pessoa saia de si mesma para de fato ver o que está fazendo", e especialmente pela sua obra Lugares $d a$ genealogia $(1991)^{8}$, Bhabha (2013) propõe pensar em uma lógica deslocada do binarismo por meio do qual geralmente são construídas identidades de diferenças (negro/branco, eu/outro). Alguém "além" de si retorna com um ímpeto de revisão e reconstrução em relação às condições políticas do presente. Sobre Lugares da genealogia, Bhabha (2013, p. 23) afirma 
O poço da escada como espaço liminar, situado no meio das designações de identidade, transforma-se no processo de interação simbólica, o tecido de ligação que constrói a diferença entre superior e inferior, negro e branco. $\mathrm{O}$ ir e vir do poço da escada, o movimento temporal e a passagem que ele propicia, evita que as identidades a cada extremidade dele se estabeleçam em polaridades primordiais. Essa passagem intersticial entre identificações fixas abre a possibilidade de um hibridismo cultural que acolhe a diferença sem uma hierarquia suposta ou imposta [...].

Sugerimos que a série Crentes e pregadores mantém uma distância ambígua da operação do estereótipo. Há uma aproximação na medida em que pretende enfatizar e reiterar de forma "ansiosa" "rótulos" como elementos organizadores de tipologias e, portanto, tende a homogeneizar representações, o que é potencializado por meio da produção de um grande volume de imagens. Em sentido contrário, ela se distancia quando a artista intitula as fotografias com nomes próprios e procura estabelecer certa aproximação dos retratados, dando relevo para particularidades e singularidades. A relação ambígua com o estereótipo também é percebida em Faz que vai de forma ainda mais explícita ao explorar o deslocamento entre identidades ou talvez pudéssemos dizer subidentidades - como uma forma de evidenciar sua heterogeneidade inerente. A representação desse trânsito entre diferentes representações identitárias nos provoca a localizar o outro não em uma polaridade fixa, mas no espaço entre, ou seja, no "entre-lugar", onde a heterogeneidade interna ao indivíduo é possível. Entre as potências da obra de Wagner está o pensar o outro para além de posições fixas, não só em relação a distintos lugares, mas como corpo no qual esses distintos lugares se inscrevem.

\section{NOTAS}

1 Termo proferido por Bárbara Wagner na palestra Arte e cotidiano, parte do evento Semana Pensamento Criativo, realizado na Caixa Cultural, em Brasília, no dia 25 de julho de 2017. Esse termo é empregado recorrentemente pela própria artista para designar seu objeto de interesse (INSTITUTO MOREIRA SALLES, 2015, on-line).

2 A obra foi encomendada pelo projeto Offside Brazil, realizado pela Magnum em parceria com o Instituto Moreira Salles por ocasião da Copa do Mundo de Futebol de 2014, no qual quatro fotógrafos e dois coletivos brasileiros (Pio Figueiroa, Breno Rotatori, André Vieira, Mídia Ninja, Garapa), juntamente a quatro fotógrafos estrangeiros (o italiano Alex Majoli, o norueguês Jonas Bendik- 
sen, e os norte-americanos David Alan Harvey e Susan Meiselas), fotografaram em cidades sede do evento buscando imagens não oficiais do torneio esportivo (INSTITUTO MOREIRA SALLES, 2015, on-line; OLIVA, 2014, on-line).

3 Informações fornecidas por Bárbara Wagner na palestra Arte e cotidiano, parte do evento Semana Pensamento Criativo, realizado na Caixa Cultural, em Brasília, no dia 25 de julho de 2017.

4 Para Mbeme (2014, p. 153), "o Estado colonial utilizaria os costumes, isto é, o princípio da diferença e da desigualdade, para fins de segregação. Seriam produzidas formas de saber específicas (a ciência colonial) com o objetivo de documentar a diferença, de eliminar a pluralidade e a ambivalência, e de fixá-la num cânone. Ô paradoxo deste processo de abstração e de reificação é o seguinte: por um lado, aparenta reconhecimento; por outro constitui por si um juízo moral, uma vez que, por fim, o costume é apenas singularizado para melhor indicar a que ponto o mundo do indígena, na sua naturalidade, em nada coincide com o nosso; isto é, não faz parte do nosso mundo e não poderia, desde logo, servir de base à experiência de uma cidadania comum."

5 Para Bhabha (2013, p. 123-124), o discurso colonial é "um aparato que se apoia no reconhecimento e repúdio de diferenças raciais/culturais/históricas. Sua função estratégica predominante é a criação de um espaço para 'povos sujeitos' através da produção de conhecimentos em termos dos quais se exerce vigilância e se estimula uma forma complexa de prazer/ desprazer. Ele busca legitimação para suas estratégias através da produção de conhecimentos do colonizador e do colonizado que são estereotipados mas avaliados antiteticamente. O objetivo do discurso colonial é apresentar o colonizado como uma população de tipos degenerados com base na origem racial de modo a justificar a conquista e estabelecer sistemas de administração e instrução.”. Esse discurso, "produz o colonizado como uma realidade social que é ao mesmo tempo um 'outro' e ainda assim inteiramente apreensível e visível."

6 Para citarmos um exemplo, a professora Magali Nascimento Cunha, referência para esse trabalho, lidera pesquisas relacionadas aos temas da religião - em especial a evangélica -, comunicação, mídia e consumo do Grupo de Pesquisa Mídia, Religião e Cultura (MIRE), vinculado ao Programa de Pós-Graduação em Comunicação da Universidade Metodista de São Paulo.

7 Informações fornecidas por Bárbara Wagner na palestra Arte e cotidiano, parte do evento Semana Pensamento Criativo, realizado na Caixa Cultural, em Brasília, no dia 25 de julho de 2017.

8 A própria Green assim descreve sua obra: "Usei a arquitetura literalmente como referência, usando o sótão, o compartimento da caldeira e o poço da escada para fazer associações entre certas divisões binárias como superior e inferior, céu e inferno. O poço da escada tornou-se um espaço liminar, uma passagem entre as áreas superior e inferior, sendo que cada uma delas recebeu placas referentes ao negro e ao branco." (apud BHABHA, 2013, p. 23). 


\section{Referências}

ABOU, Sélim, Les métamorphoses de l'identité culturelle. Diogène, n. 177, p. 4, jan./mar. 1997.

ABREU, Leandro Pimentel. O inventário como tática: a fotografia e a poética das coleções. 2011. $306 \mathrm{f}$. Tese (Doutorado em Comunicação) - Programa de Pós-Graduação da Escola de Comunicação, Universidade Federal do Rio de Janeiro, Rio de Janeiro, 2011.

APPIAH, Kwame Anthony. Identidade como problema. In: SALLUM J.R., Brasilio. et al. (Org.). Identidades. São Paulo: Editora da Universidade de São Paulo, 2016. p. 17-32.

BÁRBARA WAGNER. Disponível em:

$<$ http://cargocollective.com/barbarawagner/BARBARA-WAGNER> Acesso em: o1 fev. 2017.

BHABHA, Homi K. O local da cultura. Tradução Myriam Ávila, Eliana Lourenço de Lima Reis, Gláucia Renate Gonçalves. Belo Horizonte: Editora UFMG, 2013.

CANDAU, Joël. Memória e identidade. São Paulo: Contexto, 2016.

CUNHA, Magali Nascimento. Elucidações contemporâneas nos estudos brasileiros em mídia e religião: a perspectiva das mediações culturais e comunicacionais. Revista Famecos: mídia, cultura e tecnologia. Porto Alegre, v. 23, n. 2, maio/ago. 2016.

HALL, Stuart. A identidade cultural na pós-modernidade. Tradução Tomaz Tadeu da Silva, Guacira Lopes Louro. Rio de Janeiro: Lamparina, 2015.

INSTITUTO MOREIRA SALLES. ZUM na escola: Bárbara Wagner. 2015. Disponível em: <http://blogdoims.com.br/ zum-na-escola-barbara-wagner/> Acesso em: o1 fev. 2017. MBEMBE, Achille. Crítica da razão negra. Lisboa: Antígona, 2014.

OLIVA, Daigo. Crentes e pregadores. Folha de S. Paulo, São Paulo, 31 out. 2014. Disponível em: <http://entretempos. blogfolha.uol.com.br/2014/10/31/questoes-de-classe-e-cor-estao-para-o-crescimento-dos-evangelicos-como-manifestacoes-para-a-formacao-de-novos-eleitores-diz-barbara-wagner/> Acesso em: o1 fev. 2017.

ROSSI, Paulo José. August Sander e homens do século XX: a realidade construída. 2009. 169 f. Dissertação (Mestrado em Sociologia) - Programa de Pós-Graduação em Sociologia, Universidade de São Paulo, São Paulo, 2009.

SINGER, André Vitor. Os sentidos do lulismo: reforma gra- 
dual e pacto conservador. São Paulo: Companhia das Letras, 2012.

WAGNER, Bárbara; ANJOS, Moacir dos. Arte e cotidiano.

Caixa Cultural, Brasília. 25 jul. 2017. 
Recebido em: 13/07/2017

Aprovado em: 27/11/2017

PEDRO ERNESTO FREITAS LIMA

ped.ernesto.din@gmail.com@gmail.com

Doutorando do Programa de Pós-Graduação em Arte na linha de Teoria e História da Arte na Universidade de Brasília (UnB), Brasília, Distrito Federal, Brasil. 